\title{
Circulating Tumor Cells Undergoing the Epithelial- Mesenchymal Transition: Influence on Prognosis in Cytokeratin 19-Positive Hepatocellular Carcinoma
}

This article was published in the following Dove Press journal: OncoTargets and Therapy

\author{
Qian Zhang ${ }^{1,2, *}$ \\ Wanting Xing ${ }^{1,2, *}$ \\ Jie Zhang ${ }^{1,2}$ \\ Junwen $\mathrm{Hu}^{\mathrm{l}, 2}$ \\ Lunan $Q i^{1-3}$ \\ Bangde Xiang ${ }^{1-3}$ \\ 'Department of Hepatobiliary Surgery, \\ Guangxi Medical University Cancer \\ Hospital, Nanning, People's Republic of \\ China; ${ }^{2}$ Key Laboratory of Early \\ Prevention and Treatment for Regional \\ High Frequency Tumors, Ministry of \\ Education, Nanning, People's Republic of \\ China; ${ }^{3}$ Guangxi Liver Cancer Diagnosis \\ and Treatment Engineering and \\ Technology Research Center, Nanning, \\ People's Republic of China \\ *These authors contributed equally to \\ this work
}

Purpose: The purpose of this study was to elucidate the relationship between cytokeratin 19 (CK19) expression and levels of circulating tumor cells (CTCs) in preoperative peripheral blood of patients with hepatocellular carcinoma (HCC), and the potential influence of that relationship on prognosis.

Patients and Methods: CanPatrol ${ }^{\mathrm{TM}} \mathrm{CTC}$-enrichment technique and in situ hybridization (ISH) were used to enrich and classify CTCs undergoing the epithelial-mesenchymal transition (EMT) from blood samples of 105 HCC patients. CK19 immunohistochemistry staining was performed on HCC tissues and compared with demographic and clinical data.

Results: In total, 27 of 105 (25.7\%) HCC patients were CK19-positive. CK19-positive patients had significantly lower median tumor-free survival (TFS) than CK19-negative patients (5 vs 10 months, $\mathrm{P}=0.047)$. In total, 98 (93.3\%) patients showed pre-surgery peripheral blood CTCs (range: 0-76, median: 6), and 57 of 105 (54.3\%) patients displayed CTC counts $\geq 6$. Furthermore, CK19-positive patients with CTC count $\geq 6$ showed significantly higher percentage than CK19-negative ones $(77.8 \%$ vs $46.2 \%, \mathrm{P}=0.004)$. CK19positive patients showed a significantly higher proportion of mesenchymal CTCs among CTCs undergoing EMT than CK19-negative patients (mean rank: 62.28 vs 49.79, $\mathrm{P}=0.046$ ). We also found that CK19-positive patients with high CTC count showed significantly shorter median tumor-free survival than CK19-negative patients with low CTC count (5 vs 16 months, $\mathrm{P}=0.039$ ).

Conclusion: High CTC count and high percentage of mesenchymal CTCs are closely related to the expression of CK19, which is associated with poor prognosis in HCC patients. Keywords: hepatocellular carcinoma, cytokeratin 19, circulating tumor cells, prognosis, tumor-free survival

\section{Introduction}

Hepatocellular carcinoma (HCC) is one of the most frequent cancers and the second leading cause of death in China. ${ }^{1,2}$ HCC shows several characteristics of malignant progression that are associated with poor prognosis, including fast growth, strong invasion, easy infiltration into blood vessels and spreading through blood, as well as progression through the epithelial-mesenchymal transition (EMT). ${ }^{3}$ Despite improvement in surveillance and treatment, prognosis remains poor due to the high incidence of recurrence and metastasis. ${ }^{4}$ Currently, the concept of "precision medicine" recommends treating each patient with liver cancer differently in order to maximize the
Correspondence: Bangde Xiang; Lunan Qi Department of Hepatobiliary Surgery, Guangxi Medical University Cancer Hospital, 7I\# Hedi Road, Qingxiu District, Nanning, Guangxi, 53002I, People's Republic of China

Tel +86-77I530I253; +86-135I 7886990

Email xiangbangde@gxmu.edu.cn;

wangzhennuo@aliyun.com
OncoTargets and Therapy 2021:14 I543-1552

1543

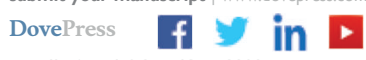

http://doi.org/| 0.21 147/OTT.S298576 
chances of survival. ${ }^{5,6}$ Therefore, early diagnosis, optimization of treatment strategies and post-treatment monitoring are very important for the management and survival of HCC patients.

Conventional imaging techniques, such as computed tomography or magnetic resonance imaging, lack sensitivity for small lesions. Serum alpha-fetoprotein (AFP) is currently an important biomarker for the early screening of HCC and monitoring after treatment, ${ }^{7}$ but it can be inaccurate. ${ }^{8,9}$

A growing body of research indicates that the monitoring of circulating tumor cells (CTCs) may be useful for the diagnosis of malignant tumors, assessment of disease, selection of treatment methods, and evaluation of prognosis. ${ }^{10-15}$ In patients with breast, rectal, or lung cancer, high numbers of CTCs in peripheral blood have been associated with higher rate of postoperative recurrence and worse response to radio- and chemotherapy. ${ }^{11,14,16}$ CTCs are rare cancer cells that have escaped from the primary solid tumor and entered the circulatory system. They function as seeds for metastases and can be classified as epithelial type (E-CTC), mesenchymal type (M-CTC), or an intermediate type in transition from epithelial to mesenchymal (E/M-CTC). These subtypes can be distinguished based on expression of surface markers. E-CTCs can be transformed into M-CTCs and vice versa. ${ }^{17,18}$

In HCC, cytokeratin 19 (CK19) is a marker of hepatic progenitor cells and acts as a key player in tumor invasion, indicating poor prognosis. ${ }^{19,20}$ Over the past years, many studies have shown that CK19-positive HCC has unique biological characteristics regarding tumor stem cells, angiogenesis, invasiveness, and tumor cell apoptosis. ${ }^{21-25}$ CK19 is closely related to epithelial-mesenchymal transition (EMT), CK19-positive cells acquire mesenchymal characteristics through the EMT and strongly proliferate due to the activation of transforming growth factor beta (TGFb)/Smad signaling. ${ }^{26}$ However, the relationship between CK19 expression and CTCs in HCC is unclear.

Therefore, based on the biological characteristics of CK19-positive tumors and the process of CTCs generation, we hypothesized that CK19 may involve in EMT transformation and increase the number of CTCs, which can result in poor prognosis of HCC patients. Therefore, the aim of our study was to investigate the potential relationship between CTC levels in peripheral blood and CK19 expression in HCC patients, and assess the potential influence of this relationship on prognosis.

\section{Patients and Methods}

\section{Patient Samples}

From March 2014 to May 2017, a total of 105 HCC patients treated with R0 resection at the Guangxi Medical University Cancer Hospital, Nanning, Guangxi Province, China, were enrolled. Flow chart of patient enrollment is shown in Figure 1. Those patients were retrospectively enrolled in the current study if they satisfied all the following inclusion criteria: (1) definitive pathological diagnosis of HCC based on the World Health Organization criteria; ${ }^{27}$ (2) Child-Pugh A stage and Performance Status Test (PST) score of 0-1; (3) no prior anticancer treatment, such as transarterial chemoembolization or radiation; and (4) R0 resection, defined as complete macroscopic removal of the tumor, negative resection margins, and no detectable intra- or extrahepatic metastatic lesions. Other relevant clinical data were obtained for each patient from medical records.

This study was conducted in accordance with the Declaration of Helsinki guidelines, and the protocol of this trial was approved by the Ethics Committee of the Tumor Hospital of Guangxi Medical University. On admission, all patients provided written consent for their medical data to be analyzed and published for research purposes.

\section{CTC Isolation and in situ Hybridization}

The CanPatrol ${ }^{\mathrm{TM}}$ system was used to isolate CTCs as previously described. ${ }^{28-31}$ Blood samples were collected 1 or 2 days before surgery. Peripheral blood samples (5 $\mathrm{mL}$, anticoagulated with ethylenediaminetetraacetic acid) were collected after discarding the first $2 \mathrm{~mL}$ to avoid contamination with skin cells. Red blood cell lysis buffer (Sur Exam, Guangzhou, China) was used to remove erythrocytes, and the cells were resuspended in phosphatebuffered saline (PBS) with 4\% formaldehyde (Sigma, St. Louis, MO, USA) for $5 \mathrm{~min}$. Next, the blood was filtered using a system including a filtration tube containing a $8-\mu \mathrm{m}$ pore membrane (Sur Exam), a manifold vacuum plate with valve settings (SurExam), an E-Z96 vacuum manifold (Omega, Norcross, GA, USA), and a vacuum pump (Auto Science, Tianjin, China). The pumping pressure was $0.08 \mathrm{MPa}^{32}$

In situ hybridization was used to detect mRNAs encoding EpCAM, CK8/18/19 (as epithelial biomarkers), or Vimentin and Twist (as mesenchymal biomarkers). The 


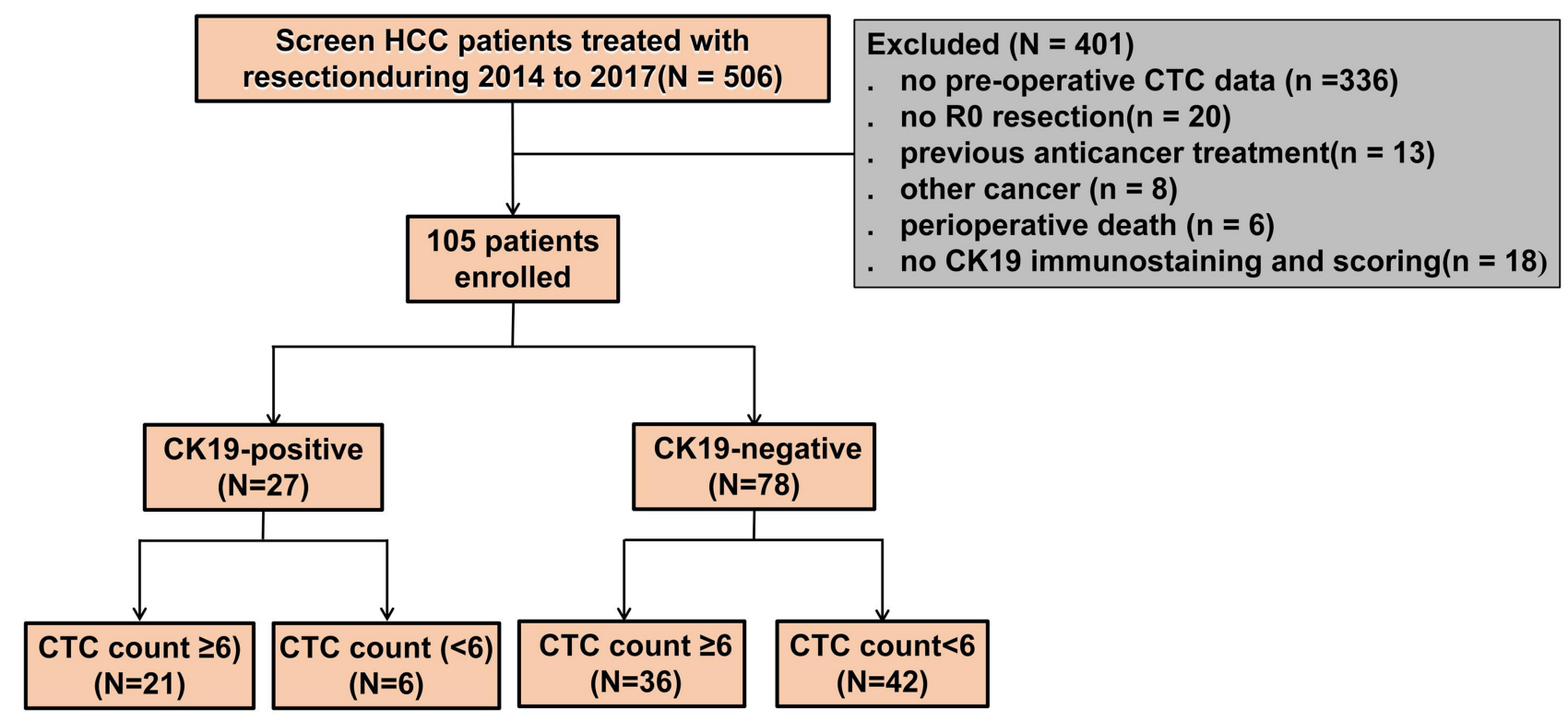

Figure I Flow chart of patient enrollment.

Notes: The 105 patients were divided into two sub-groups based on median CTC counts: patients were classified as having low total CTC count (>6) and as having high total CTC count $(\geq 6)$

assay was performed in a 24-well plate (Corning, NY, USA), and the cells on the membrane were treated with a protease (Qiagen, Hilden, Germany) before hybridization with probe as previously described. ${ }^{11,31,33}$

\section{CK 19 Immunostaining and Scoring}

Immunohistochemistry of HCC tissue samples after surgery was performed as previously described. ${ }^{34}$ Postoperative specimens were fixed in $10 \%$ formalin, embedded in paraffin, cut into $4-\mu \mathrm{m}$ sections, deparaffinized in xylene and rehydrated through graded alcohol solutions. Antigen retrieval was performed for 2-3 $\mathrm{min}$ at $100^{\circ} \mathrm{C}$ in $10 \mathrm{mmol} / \mathrm{L}$ citrate buffer $(\mathrm{pH} 6.0)$ in a microwave oven. Endogenous peroxidases were blocked by immersing the sections in 3\% hydrogen peroxide for 15 min. Sections were then incubated at $37^{\circ} \mathrm{C}$ for 1 hour with mouse antibody against CK19 (diluted 1:200; Kit-0030, Maixin, Fuzhou, China). Tissue sections were rinsed with PBS, incubated with anti-rabbit or -mouse immunoglobulin (Kit-5030; Maixin) diluted in PBS for $20 \mathrm{~min}$ at $25^{\circ} \mathrm{C}$, and rinsed again with PBS. Finally, the samples were incubated with horseradish peroxidase-conjugated antibody for $10 \mathrm{~min}$, rinsed in PBS, incubated with diaminobenzidine for $10 \mathrm{~min}$, and counterstained with hematoxylin. CK19-positive tissue slices supplied with the immunostaining kits were analyzed in parallel with patient samples as positive controls and negative controls (by replacing primary antibody with PBS).
The proportion of all cells in the field of view of a section that stained for CK19 was determined independently by two senior pathologists who were blinded to clinical and follow-up data. When the proportion was $>5 \%$, the section was considered CK19-positive. Proportions of $5-10 \%$ were considered weak expression, while proportions $>10 \%$ were considered strong expression.

\section{Patient Follow-Up}

The 105 patients were followed up every 1-2 months for the first year and every 3 months thereafter, with a final follow-up date of September 30, 2019. Postoperative follow-up consisted of one or more of the following tests: serum AFP measurement, ultrasonography, dynamic computed tomography (CT), and magnetic resonance imaging (MRI). Recurrence was diagnosed based on elevated AFP levels and findings on at least one of the three imaging modalities. $^{35}$

\section{Statistical Analysis}

All statistical analyses were performed with SPSS version 25 for Windows (IBM, Armonk, NY, USA). Scatter plots were plotted using GraphPrism Version 5.0 (GraphPad Software, La Jolla, CA, USA).

The rates of individuals with a given clinical or pathological characteristic, including a certain CTC count, were reported as $\mathrm{n}(\%)$. Differences between groups were 
assessed for significance using the Pearson chi-squared test or Fisher's exact tests if any cell number less than 5 . Differences between patients with other CTC levels were assessed using the Mann-Whitney $U$-test because the data were not normally distributed.

A Kaplan-Meier curve with a Log rank test was performed to compare the tumor-free-survival (TFS) time between levels of CK19 expression or other groups. All statistical assessments were two-tailed, and differences associated with $\mathrm{p}<0.05$ were considered statistically significant.

\section{Results}

\section{Patient Characteristics and Clinical Outcomes}

A total of $105 \mathrm{HCC}$ patients with $\mathrm{R} 0$ resection (91 males and 14 females) with a mean age of 46.2 years (range: 20-72 years) were enrolled. Nearly half $(43,41.0 \%)$ were younger than 45 years, 75 (71.4\%) had HBV-DNA levels $\geq 5.0 \times 10^{2}, 59(56.2 \%)$ had AFP levels $\geq 400 \mathrm{ng} / \mathrm{mL}, 40$ (38.1\%) presented multiple tumors, $48(45.7 \%)$ were in BCLC stages B-C and 41 (39.0\%) were incomplete tumor capsule. The demographic and clinical characteristics of the enrolled patients are summarized in Table 1 .

\section{CKI9 Immunostaining Levels and TFS}

CK19 expression was detected in 27 of 105 (25.7\%) HCC cases (Table 2, Figure 2A). TFS analyses showed that CK19-positive HCC patients had significantly shorter TFS than patients with CK19-negative tumors (median TFS:5 vs 10 months, $\mathrm{P}=0.047$ ) (Figure $2 \mathrm{~B}$ ). We also found that the characteristics of age $<45, \mathrm{AFP} \geq 400 \mathrm{ng} / \mathrm{mL}$, and incomplete tumor capsule were more frequent among CK19-positive patients than CK19-negative ones (Table 2, Figure 2C-E). However, CK19 expression did not vary significantly with patient sex, HBsAg level, HBV-DNA level, tumor size, number of tumors, liver cirrhosis, Edmondson grade, BCLC stage, microvascular invasion (MVI) or portal vein tumor thrombus (PVTT) (Table 2).

\section{CTC Subpopulations in Blood and} Relationships to Clinical Characteristics

Using the CanPatrol ${ }^{\mathrm{TM}} \mathrm{CTC}$-enrichment technique, we measured the number of CTCs in the blood samples of 105 HCC patients before surgery. The green and red fluorescent signals represent mesenchymal or epithelial gene expression, respectively. Three subpopulations were identified: E-CTCs (Figure 3A), E/M-CTCs (Figure 3B), and M-CTCs (Figure 3C).
Table I Demographic and Clinical Characteristics of the 105 HCC Patients

\begin{tabular}{|c|c|c|}
\hline Variables & Categories & n (\%) \\
\hline Age (years) & $<45$ vs. $\geq 45$ & $43(4 I)$ vs $62(59)$ \\
\hline Sex & Male vs. Female & 91 (86.7) vs I4 (13.3) \\
\hline $\mathrm{HBsAg}$ & Negative vs. Positive & $12(11.4)$ vs $93(88.6)$ \\
\hline HBV-DNA & $<5.0 \times 10^{2}$ vs. $\geq 5.0 \times 10^{2}$ & $30(28.6)$ vs $75(7 \mid .4)$ \\
\hline $\operatorname{AFP}(\mathrm{ng} / \mathrm{mL})$ & $<400$ vs. $\geq 400$ & $46(43.8)$ vs 59 (56.2) \\
\hline Tumor size $(\mathrm{cm})$ & $<5$ vs. $\geq 5$ & $23(21.9)$ vs $82(78.1)$ \\
\hline Tumor number & Single vs. Multiple & $65(61.9)$ vs $40(38.1)$ \\
\hline Liver cirrhosis & Negative vs. Positive & $4(3.8)$ vs 101 (96.2) \\
\hline Edmondson Grade & I-II vs. III-IV & $63(60.0)$ vs $42(40.0)$ \\
\hline BCLC stage & $0-A$ vs. $B-C$ & $57(54.3)$ vs $48(45.7)$ \\
\hline Tumor Capsule & Complete vs. Incomplete & $64(6 \mid .0)$ vs 4 I (39.0) \\
\hline MVI & Negative vs. Positive & $33(31.4)$ vs $72(68.6)$ \\
\hline PVTT & Negative vs. Positive & $82(78.1)$ vs $23(21.9)$ \\
\hline
\end{tabular}

Abbreviations: AFP, alpha-fetoprotein; BCLC stage, Barcelona Clinic Liver Cancer stage; $\mathrm{HBsAg}$, hepatitis $B$ surface antigen; $\mathrm{HBV}-\mathrm{DNA}$, hepatitis $B$ virus DNA; $\mathrm{HCC}$, hepatocellular carcinoma; MVI, microvascular invasion; PVTT, portal vein tumor thrombosis.

CTCs were detected in $98(93.33 \%)$ of the 105 HCC patients. The preoperative median CTC count was 6 (range, 0-76). The 105 patients were divided into two sub-groups based on median CTC count: 48 (45.7\%) patients were classified as having low total CTC count $(<6)$ and $57(54.3 \%)$ as having high CTC count $(\geq 6)$ (Table 3).

Significantly higher CTC counts were found in patients with $\mathrm{AFP} \geq 400 \mathrm{ng} / \mathrm{mL}$, multiple tumors, HBV DNA $\geq 5.0 \times 10^{2}$ and advanced HCC (BCLC B-C stage) (Table 3, Figure 3DG). However, CTC counts did not vary significantly with patient age, sex, HBsAg level, tumor size, liver cirrhosis, Edmondson grade, tumor capsule, MVI or PVTT.

\section{Association of CKI9 Levels with CTC Count or Type}

CK19-positive patients with high CTC count showed significantly higher CTC percentage (77.8\%) than CK19negative patients $(46.2 \%, \mathrm{P}=0.004)$ (Figure 4A). Further analysis revealed that CTCs in peripheral blood of CK19-positive patients were mainly of the M-CTC type, whereas more CTCs were of the E-CTC type in CK19-negative patients (Table 4). 
Table 2 Comparison of Clinicopathological Characteristics Between HCC Patients Positive or Negative for CKI9

\begin{tabular}{|c|c|c|c|}
\hline \multirow[t]{2}{*}{ Variables } & CKI9-Negative & CKI9-Positive & \multirow[t]{2}{*}{$P$ value } \\
\hline & $n=78$ & $n=27$ & \\
\hline \multicolumn{4}{|l|}{ Age (years) } \\
\hline$<45$ & $27(34.6)$ & $16(59.3)$ & \multirow[t]{2}{*}{$0.025^{*}$} \\
\hline$\geq 45$ & $51(65.4)$ & II (40.7) & \\
\hline \multicolumn{4}{|l|}{ Sex } \\
\hline Male & 67 (85.9) & $24(88.9)$ & \multirow[t]{2}{*}{0.693} \\
\hline Female & II (I4.I) & $3(11.1)$ & \\
\hline \multicolumn{4}{|l|}{ HBsAg } \\
\hline Negative & $8(10.3)$ & $4(14.8)$ & \multirow[t]{2}{*}{0.771} \\
\hline Positive & 70 (89.7) & $23(85.2)$ & \\
\hline \multicolumn{4}{|l|}{ HBV-DNA } \\
\hline$<5.0 \times 10^{2}$ & $24(30.8)$ & $6(22.2)$ & \multirow[t]{2}{*}{0.397} \\
\hline$\geq 5.0 \times 10^{2}$ & $54(69.2)$ & $21(77.8)$ & \\
\hline \multicolumn{4}{|c|}{ AFP (ng/mL) } \\
\hline$<400$ & $39(50.0)$ & $7(25.9)$ & \multirow[t]{2}{*}{$0.030 *$} \\
\hline$\geq 400$ & $39(50.0)$ & $20(74.1)$ & \\
\hline \multicolumn{4}{|c|}{ Tumor size (cm) } \\
\hline$<5$ & $19(24.4)$ & $4(14.8)$ & \multirow[t]{2}{*}{0.301} \\
\hline$\geq 5$ & $59(75.6)$ & $23(85.2)$ & \\
\hline \multicolumn{4}{|c|}{ Tumor number } \\
\hline Single & $48(6 \mid .5)$ & $17(63.0)$ & \multirow[t]{2}{*}{0.895} \\
\hline Multiple & $30(38.5)$ & $10(37.0)$ & \\
\hline \multicolumn{4}{|c|}{ Liver cirrhosis } \\
\hline Negative & $4(5.1)$ & 0 & \multirow[t]{2}{*}{0.538} \\
\hline Positive & 74 (94.9) & $27(100)$ & \\
\hline \multicolumn{4}{|c|}{ Edmondson grade } \\
\hline III-IV & $28(35.9)$ & $14(5 \mid .9)$ & \multirow[t]{2}{*}{0.145} \\
\hline I-II & $50(64.1)$ & $13(48.1)$ & \\
\hline \multicolumn{4}{|c|}{ BCLC stage } \\
\hline $0-A$ & $42(53.8)$ & $15(55.6)$ & \multirow[t]{2}{*}{0.878} \\
\hline$B-C$ & $36(46.2)$ & $12(44.4)$ & \\
\hline
\end{tabular}

(Continued)
Table 2 (Continued).

\begin{tabular}{|c|c|c|c|}
\hline \multirow[t]{2}{*}{ Variables } & CKI9-Negative & CKI9-Positive & \multirow[t]{2}{*}{$P$ value } \\
\hline & $n=78$ & $n=27$ & \\
\hline \multicolumn{4}{|c|}{ Tumor capsule } \\
\hline Complete & $52(66.7)$ & $12(44.4)$ & \multirow[t]{2}{*}{$0.04 I^{*}$} \\
\hline Incomplete & $26(33.3)$ & I5 (55.6) & \\
\hline \multicolumn{4}{|l|}{ MVI } \\
\hline Negative & $26(33.3)$ & $7(25.9)$ & \multirow[t]{2}{*}{0.475} \\
\hline Positive & $52(66.7)$ & $20(74.1)$ & \\
\hline \multicolumn{4}{|l|}{ PVTT } \\
\hline Negative & $63(80.8)$ & $19(70.4)$ & \multirow[t]{2}{*}{0.260} \\
\hline Positive & $15(19.2)$ & $8(29.6)$ & \\
\hline
\end{tabular}

Notes: Values are $n$ (\%); $\mathrm{P}<0.05$ was considered significant; ${ }^{*} \mathrm{p}<0.05$. Abbreviations: AFP, alpha-fetoprotein; BCLC stage, Barcelona Clinic Liver Cancer stage; CK 19, cytokeratin 19; HCC, hepatocellular carcinoma; HBV-DNA, hepatitis $B$ virus $\mathrm{DNA}$; $\mathrm{HBs} A g$, hepatitis $B$ surface antigen; $\mathrm{MVl}$, microvascular invasion; PVTT, portal vein tumor thrombosis.

Our analysis found that the median TFS of the different groups were 5.0 months for CK19-positive patients with high CTC count, 7.0 months for CK19-negative patients with high CTC count, 7.0 months for CK19-positive patients with low CTC count, and 16.0 months for CKnegative patients with low CTC count. Among the four groups, patients who had high CTC count and were CK19positive had significantly lower TFS ( $<<0.05$ ) (Figure 4B).

\section{Discussion}

The high recurrence and metastasis rates of $\mathrm{HCC}$ after radical surgery reduce survival. Therefore, early diagnosis of HCC and post-treatment monitoring are key for comprehensive treatment and management of these patients. At present, clinical indicators to predict postoperative recurrence are rare. Therefore, we explored the postoperative prognosis of HCC through the evaluation of preoperative peripheral blood CTCs levels as well as CK19 expression in postoperative cancer tissues.

CK19-positive HCC cells show a high degree of malignancy, including invasion and other aggressive behaviors. ${ }^{26,36-38}$ A previous study showed that the median disease-free survival time of CK19-positive HCC patients was significantly shorter than that of CK19-negative 

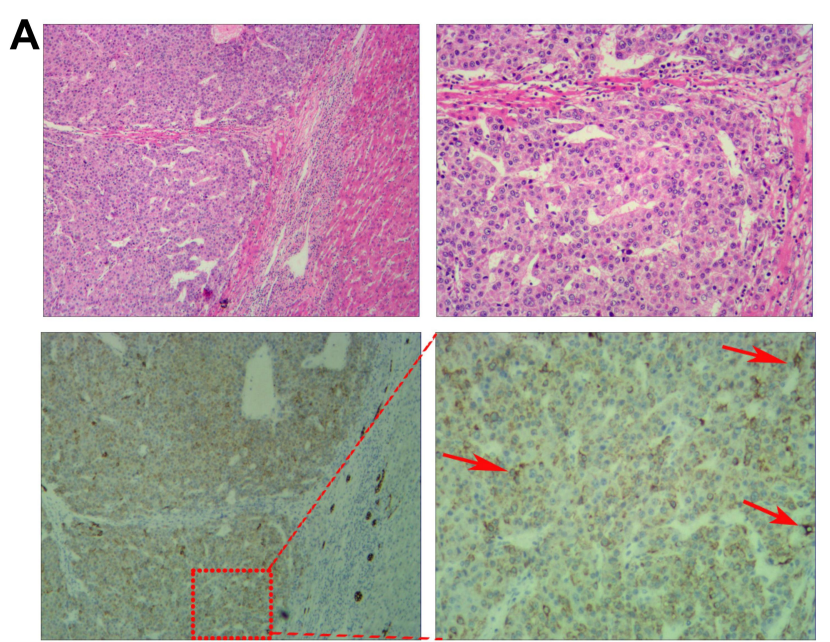

C

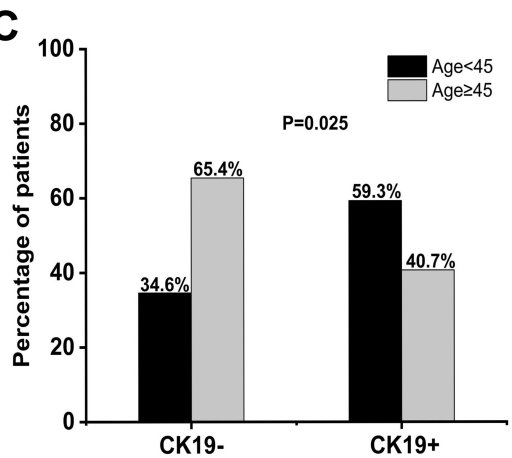

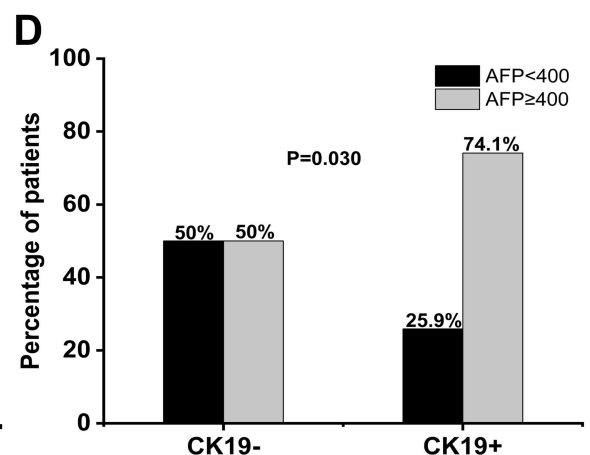
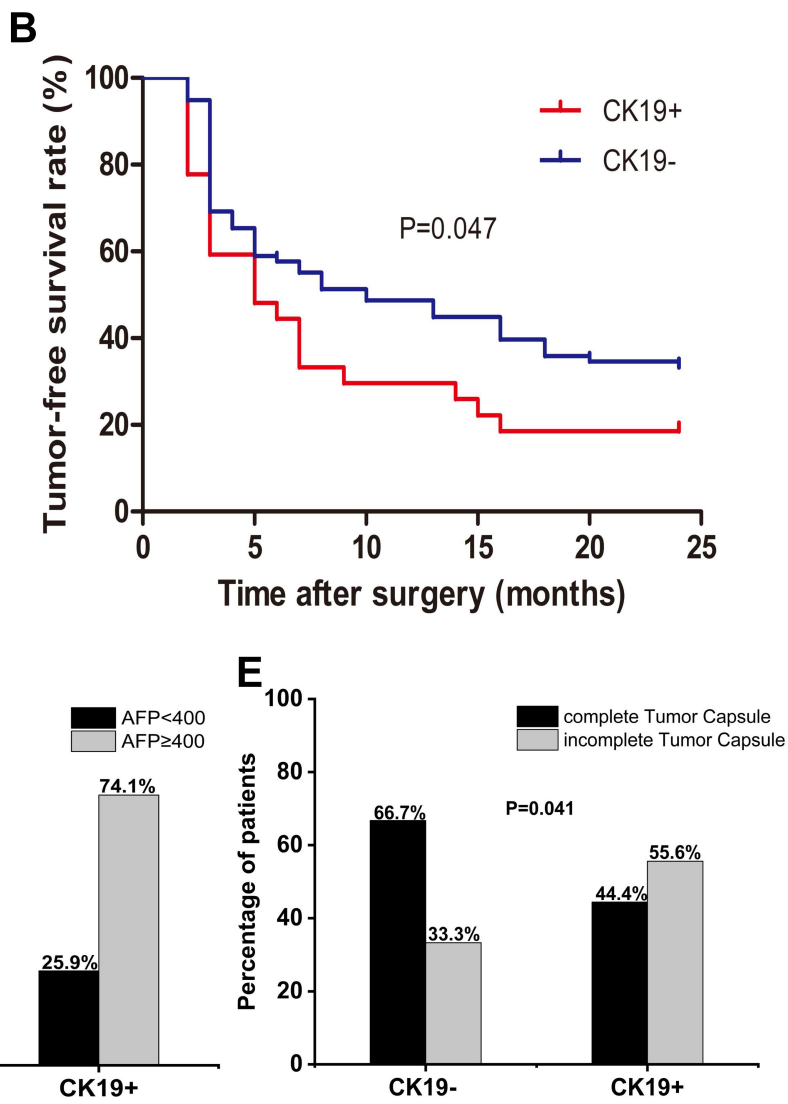

Figure 2 Immunostaining and prognostic significance of CKI9. (A) Tumor sections of the same patient were analyzed by hematoxylin and eosin staining (top) and immunohistochemical staining against CKI9 (bottom). The arrowheads was used to indicate a few strong examples of CKI9 staining. (B) Tumor-free survival after surgery among patients in CK19- or CK19+ patients. The Kaplan-Meier curve was determined by the Log rank test. Comparison of CK19 expression between CK 19- or CKI9+ patients stratified by age (C), alpha-fetoprotein (AFP) level (D) or complete of tumor capsule (E). Difference analysis were assessed for significance using the Pearson chisquared test.
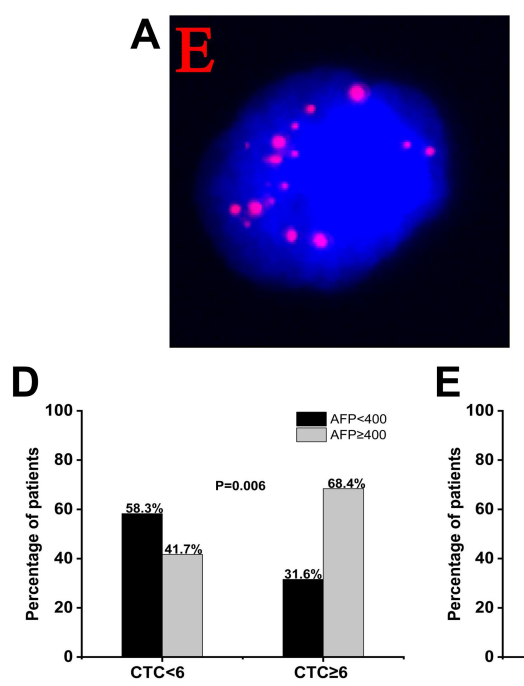

E
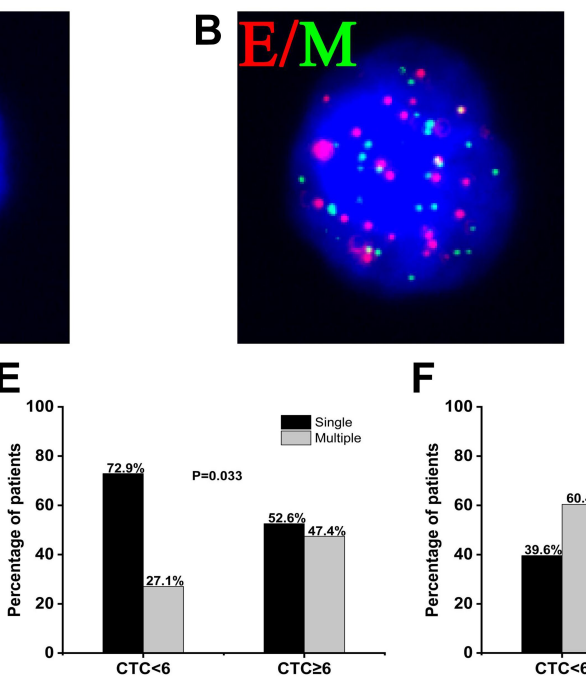

$\mathbf{F}$

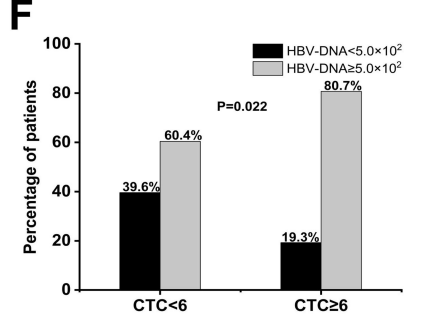

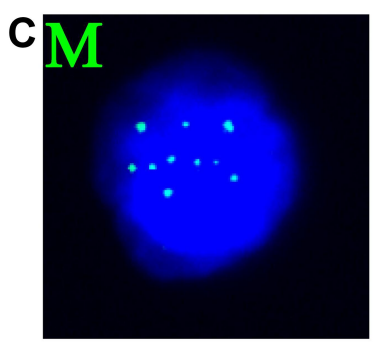

G

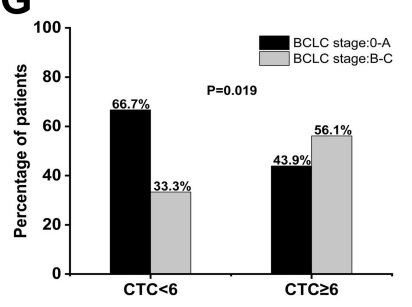

Figure 3 Circulating tumor cell (CTC) subpopulations and their relationship with survival. CTCs were stained for epithelial markers (EpCAM and CK8/I8/I9, red fluorescence) and mesenchymal markers (Vimentin and Twist, green fluorescence) and classified as epithelial CTCs (E-CTCs) (A), epithelial/mesenchymal hybrid CTCs (E/ M-CTCs) (B) or mesenchymal CTCs (M-CTCs) (C). Comparison of CTC counts in patients stratified by alpha-fetoprotein (AFP) level (D), tumor number (E), hepatitis B virus (HBV) DNA (F), and Barcelona Clinic Liver Cancer (BCLC) stage (G). Difference analysis were assessed for significance using the Pearson chi-squared test. 
Table 3 Comparison of Clinicopathological Characteristics Between HCC Patients with Low (<6) or High ( $\geq 6)$ CTC Counts

\begin{tabular}{|c|c|c|c|}
\hline \multirow[t]{2}{*}{ Variables } & СТC $<6$ & CTC $\geq 6$ & \multirow[t]{2}{*}{$P$ value } \\
\hline & $n=48$ & $n=57$ & \\
\hline \multicolumn{4}{|l|}{ Age (years) } \\
\hline$<45$ & $15(3 \mid .2)$ & $28(49.1)$ & \multirow[t]{2}{*}{0.064} \\
\hline$\geq 45$ & $33(68.8)$ & $29(50.9)$ & \\
\hline \multicolumn{4}{|l|}{ Sex } \\
\hline Male & $40(83.3)$ & $51(89.5)$ & \multirow[t]{2}{*}{0.356} \\
\hline Female & $8(16.7)$ & $6(10.5)$ & \\
\hline \multicolumn{4}{|l|}{ HBsAg } \\
\hline Negative & $6(12.5)$ & $6(10.5)$ & \multirow[t]{2}{*}{0.751} \\
\hline Positive & $42(87.5)$ & $51(89.5)$ & \\
\hline \multicolumn{4}{|l|}{ HBV-DNA } \\
\hline$<5.0 \times 10^{2}$ & $19(39.6)$ & II (19.3) & \multirow[t]{2}{*}{$0.022 *$} \\
\hline$\geq 5.0 \times 10^{2}$ & $29(60.4)$ & $46(80.7)$ & \\
\hline \multicolumn{4}{|c|}{ AFP (ng/mL) } \\
\hline$<400$ & $28(58.3)$ & $18(31.6)$ & \multirow[t]{2}{*}{$0.006 *$} \\
\hline$\geq 400$ & $20(4 I .7)$ & $39(68.4)$ & \\
\hline \multicolumn{4}{|c|}{ Tumor size $(\mathrm{cm})$} \\
\hline$<5$ & $13(27.1)$ & $10(17.5)$ & \multirow[t]{2}{*}{0.239} \\
\hline$\geq 5$ & 35 (72.9) & $47(82.5)$ & \\
\hline \multicolumn{4}{|c|}{ Tumor number } \\
\hline Single & 35 (72.9) & $30(52.6)$ & \multirow[t]{2}{*}{$0.033^{*}$} \\
\hline Multiple & $13(27.1)$ & $27(47.4)$ & \\
\hline \multicolumn{4}{|c|}{ Liver cirrhosis } \\
\hline Negative & $4(8.3)$ & 0 & \multirow[t]{2}{*}{0.087} \\
\hline Positive & 44 (9l.7) & $57(100)$ & \\
\hline \multicolumn{4}{|c|}{ Edmondson grade } \\
\hline III-IV & $16(33.3)$ & $26(45.6)$ & \multirow[t]{2}{*}{0.201} \\
\hline I-II & $32(66.7)$ & $31(54.4)$ & \\
\hline \multicolumn{4}{|c|}{ BCLC stage } \\
\hline $0-A$ & $32(66.7)$ & 25 (43.9) & \multirow[t]{2}{*}{$0.019 *$} \\
\hline$B-C$ & $16(33.3)$ & $32(56.1)$ & \\
\hline
\end{tabular}

(Continued)
Table 3 (Continued).

\begin{tabular}{|c|c|c|c|}
\hline \multirow[t]{2}{*}{ Variables } & CTC $<6$ & CTC $\geq 6$ & \multirow[t]{2}{*}{$P$ value } \\
\hline & $n=48$ & $n=57$ & \\
\hline \multicolumn{4}{|c|}{ Tumor capsule } \\
\hline Complete & $34(70.8)$ & $30(52.6)$ & \multirow[t]{2}{*}{0.057} \\
\hline Incomplete & 14 (29.2) & $27(47.4)$ & \\
\hline \multicolumn{4}{|l|}{ MVI } \\
\hline Negative & $17(35.4)$ & $16(28.1)$ & \multirow[t]{2}{*}{0.419} \\
\hline Positive & $31(64.6)$ & $4 I$ (7I.9) & \\
\hline \multicolumn{4}{|l|}{ PVTT } \\
\hline Negative & $41(85.4)$ & $4 I$ (7I.9) & \multirow[t]{2}{*}{0.096} \\
\hline Positive & $7(14.6)$ & $16(28.1)$ & \\
\hline
\end{tabular}

Notes: Values are $n$ (\%); $\mathrm{P}<0.05$ was considered significant; ${ }^{*} \mathrm{p}<0.05$. Abbreviations: AFP, alpha-fetoprotein; BCLC stage, Barcelona Clinic Liver Cancer stage; CTCs, circulating tumor cells; HCC, hepatocellular carcinoma; HBV-DNA, hepatitis $B$ virus DNA; HBsAg, hepatitis B surface antigen; MVl, microvascular invasion; PVTT, portal vein tumor thrombosis.

patients among those undergoing radiofrequency ablation. ${ }^{39}$ Consistently, we found that TFS was shorter for CK19positive patients than for CK19-negative ones. Hepatocellular carcinoma recurrence is divided into early recurrence (less than 2 years) and late recurrence (more than 2 years) according to the time to recurrence after surgery. ${ }^{40-42}$ The mechanisms of early and late recurrence are different. ${ }^{43-46}$ The presence of CTCs reflects the aggressiveness of a solid tumor. A previous study by our group showed that high CTC counts before resection were significantly associated with early recurrence of HCC. ${ }^{31}$ The current work showed that CK19-positive patients had higher CTC counts than CK19-negative ones. We extended those findings in the present study by showing that high CTC count and CK19 express positive showed significantly lower tumor-free survival than patients with low CTC count and CK19-negative. These results suggest that CK19 contributes to poor prognosis.

We also found that CTCs in peripheral blood of CK19positive patients were mainly of the M-CTC type, whereas more CTCs were of the E-CTC type in CK19-negative patients. M-CTCs are regarded as the most malignant CTC. ${ }^{31}$ A previous study revealed that CK19-positive cells in HCC possess Cancer stem cells (CSCs) characteristics are 

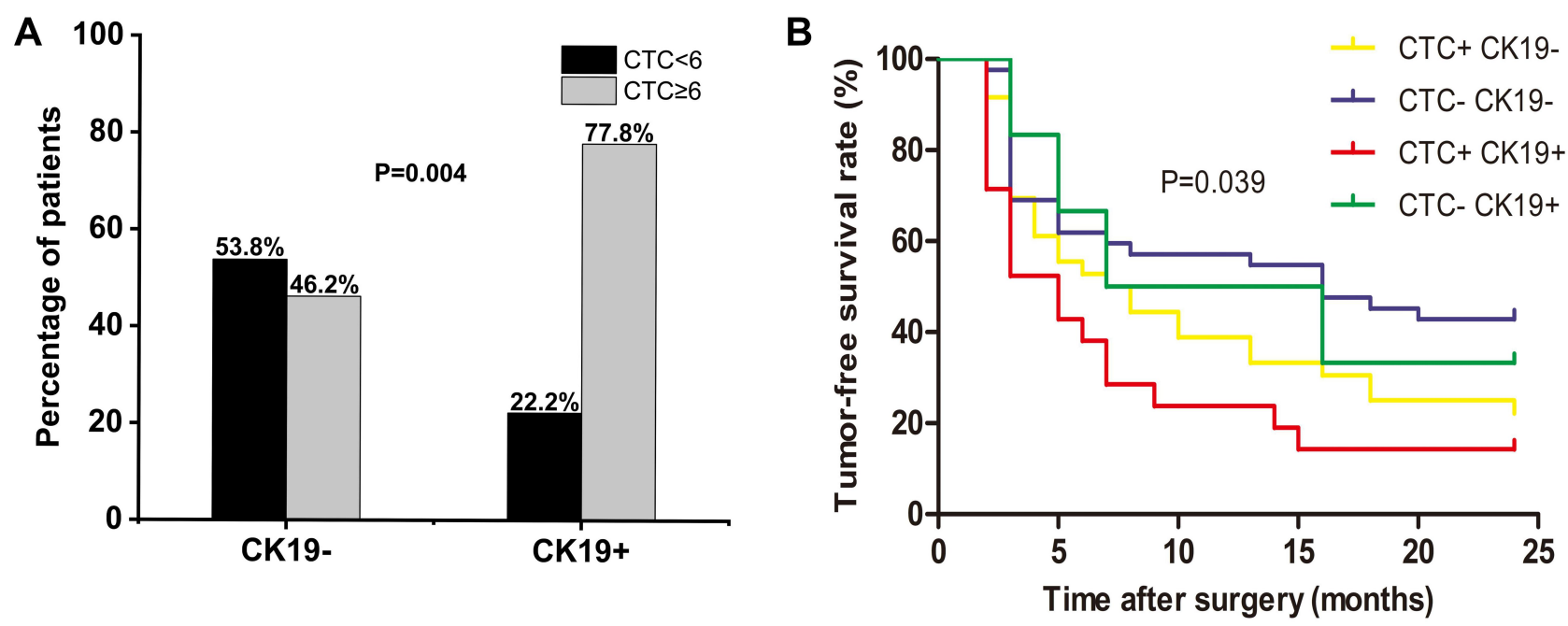

Figure 4 Association of CTC counts with CKI9 immunostaining, and survival analysis based on this association. (A) Comparison of CK I9- or CKI9+ patients stratified by CTC count $<6$ or $\geq 6$. Difference analysis were assessed for significance using the Pearson chi-squared test. P<0.05 was considered statistically significant. (B) Tumor-free survival after surgery among patients stratified by both CKI 9 expression and CTC count. The Kaplan-Meier curve was determined by the Log rank test.

closely related to the EMT, and that CK19-positive cells express several genes associated with the EMT and show higher motility and migration than CK19-negative cells. ${ }^{26}$ EMT enhances tumor mobility and invasiveness and is believed to facilitate metastasis. ${ }^{47-49}$ During EMT, cancer cells lose some of their epithelial characteristics and acquire more migratory mesenchymal cell-like characteristics, undergoing major changes in their cytoskeleton. ${ }^{50,51}$ Our results suggest that high levels of M-CTCs are closely related to the expression of $\mathrm{CK} 19$ and lead to a poor prognosis in patients with CK19-positive HCC. CK19 may regulate EMT and promote an increase in the number of CTCs, ultimately leading to poor prognosis.

Interestingly, we found from the postoperative clinical results of HCC patients that those with CK19-positive HCC

Table 4 Distribution of CTCs' Types in 105 HCC Patients Positive or Negative for CKI9

\begin{tabular}{|l|c|c|c|c|c|}
\hline \multirow{2}{*}{$\begin{array}{l}\text { CTCs' } \\
\text { Type }\end{array}$} & \multicolumn{2}{|c|}{ Mean Rank } & U & Z & P value \\
\cline { 2 - 4 } & $\begin{array}{c}\text { CK19 } \\
\text { Positive }\end{array}$ & $\begin{array}{c}\text { CK19 } \\
\text { Negative }\end{array}$ & & & \\
\hline All CTCs & 65.54 & 48.66 & 714.50 & -2.488 & $0.013^{*}$ \\
\hline E-CTC & 56.00 & 51.96 & 972.00 & -6.04 & 0.546 \\
\hline M-CTC & 62.28 & 49.79 & 802.50 & -1.991 & $0.046^{*}$ \\
\hline E/M-CTC & 62.50 & 49.71 & 796.50 & -1.896 & 0.058 \\
\hline
\end{tabular}

Notes: $\mathrm{P}<0.05$ was considered significant; * $\mathrm{p}<0.05$

Abbreviations: CK19, cytokeratin 19; CTCs, circulating tumor cells; E-CTC, epithelial CTCs; M-CTC, mesenchymal CTCs; E/M-CTC, epithelial/mesenchymal hybrid CTCs. were younger, had higher serum AFP levels and showed lower rates of tumor envelope formation than those with CK19-negative HCC. These results suggest that the expression of CK19 in HCC increases tumor invasiveness.

This study presents several limitations. First, our cohort was relatively small. To overcome this limitation, we will further verify this conclusion in follow-up research and will conduct research in a multi-center cohort. In addition, the present study was conducted only at the clinical level. Molecular studies are needed to elucidate the causes of poor prognosis in CK19-positive patients with high CTCs in peripheral blood. This may help to find a new target for "precise therapy" for CK19-positive HCC patients with high preoperative CTC counts.

\section{Conclusion}

High CTC count and high M-CTC percentage are closely related to the expression of CK19 in HCC, which in turn is associated with recurrence. The preoperative number of CTCs undergoing EMT may be significantly higher in CK19-positive HCC patients than in CK19-negative patients. In CK-19 positive patients, the main CTC type may be mesenchymal. Preoperative CTC analysis combined with postoperative analysis of CK19 expression may be a new method for predicting prognosis of HCC patients after surgery.

\section{Acknowledgments}

This work was supported by grants from the National Natural Science Foundation of China (81960450), 
National Major Special Science and Technology Project (2017ZX10203207), The Key Research and Development Project of Guangxi (AA18221001, AB18050020), Highlevel innovation team and outstanding scholar program in Guangxi Colleges and Universities, "139" projects for training of high-level medical science talents from Guangxi(G201903001). The funding agencies had no role in study design, data collection and analysis, decision to publish, or preparation of the manuscript.

\section{Disclosure}

The authors report no conflicts of interest in this work.

\section{References}

1. Bray F, Ferlay J, Soerjomataram I, Siegel RL, Torre LA, Jemal A. Global cancer statistics 2018: GLOBOCAN estimates of incidence and mortality worldwide for 36 cancers in 185 countries. CA Cancer J Clin. 2018;68:394-424.

2. Zhou M, Wang H, Zeng XY, et al. Mortality, morbidity, and risk factors in China and its Provinces, 1990-2017: a systematic analysis for the Global Burden of Disease Study 2017. Lancet. 2019; 10204:1145-1158. doi:10.1016/S0140-6736(19)30427-1

3. Yang B, Li M, Tang W, et al. Dynamic network biomarker indicates pulmonary metastasis at the tipping point of hepatocellular carcinoma. Nat Commun. 2018;9(1):678. doi:10.1038/s41467-01803024-2

4. Llovet JM, Hernandez-Gea V. Hepatocellular carcinoma: reasons for phase III failure and novel perspectives on trial design. Clin Cancer Res. 2014;20(8):2072-2079. doi:10.1158/1078-0432.CCR-13-0547

5. Liang Q, Shen X, Sun G. Precision medicine: update on diagnosis and therapeutic strategies of hepatocellular carcinoma. Curr Med Chem. 2017;8(17):1999-2008. doi:10.2174/09298673256661801171 01532

6. Llovet JM, Montal R, Sia D, Finn RS. Molecular therapies and precision medicine for hepatocellular carcinoma. Nat Rev Clin Oncol. 2018;15(10):599-616. doi:10.1038/s41571-018-0073-4

7. Kudo M. Evidence and consensus on the management of hepatocellular carcinoma: update 2015. Oncology. 2015;89(2):1-3. doi:10.11 $59 / 000440624$

8. Mehta NJ, Celik AD, Peters MG. Screening for hepatocellular carcinoma: what is missing? Hepatol Commun. 2017;1(1):18-22. doi:10.1002/hep4.1014

9. Morimoto M, Numata K, Nozaki A, et al. Novel lens culinaris agglutinin-reactive fraction of $\alpha$-fetoprotein: a biomarker of hepatocellular carcinoma recurrence in patients with low $\alpha$-fetoprotein concentrations. Int J Clin Oncol. 2012;17(4):373-379. doi:10.1007/ s10147-011-0306-3

10. Sun Y, Xu Y, Yang X, et al. Circulating stem cell-like epithelial cell adhesion molecule-positive tumor cells indicate poor prognosis of hepatocellular carcinoma after curative resection. Hepatology. 2013;4:1458-1468. doi:10.1002/hep.26151

11. Yu M, Bardia A, Wittner BS, et al. Circulating breast tumor cells exhibit dynamic changes in epithelial and mesenchymal composition. Science. 2013;339(6119):580-584. doi:10.1126/science.1228522

12. Alix-Panabières C, Pantel K. Challenges in circulating tumour cell research. Nat Rev Cancer. 2014;14(9):623-631. doi:10.1038/nrc3820

13. Bruix J, Reig M, Sherman M. Evidence-based diagnosis, staging, and treatment of patients with hepatocellular carcinoma. Gastroenterology. 2016;150(4):835-853. doi:10.1053/j.gastro.2015. 12.041
14. Sun W, Li G, Wan J, Zhu J, Shen W, Zhang Z. Circulating tumor cells: a promising marker of predicting tumor response in rectal cancer patients receiving neoadjuvant chemo-radiation therapy. Oncotarget. 2016;7(43):69507-69517. doi:10.18632/oncotarget.10 875

15. Li X, Wang H, Li T, et al. Circulating tumor DNA/circulating tumor cells and the applicability in different causes induced hepatocellular carcinoma. Curr Probl Cancer. 2019;2:100516.

16. Hou JM, Krebs M, Ward T, et al. Circulating tumor cells as a window on metastasis biology in lung cancer. Am J Pathol. 2011;3:989-996. doi:10.1016/j.ajpath.2010.12.003

17. Bednarzknoll N, Alixpanabieres C, Pantel K. Plasticity of disseminating cancer cells in patients with epithelial malignancies. Cancer Metastasis Rev. 2012;3:673-687. doi:10.1007/s10555-012-9370-z

18. Nieto MA, Huang RYJ, Jackson RA, Thiery JP. Emt: 2016. Cell. 2016;1:21-45.

19. Durnez A, Verslype C, Nevens F, et al. The clinicopathological and prognostic relevance of cytokeratin 7 and 19 expression in hepatocellular carcinoma. A possible progenitor cell origin. Histopathology. 2006;2:138-151. doi:10.1111/j.1365-2559.2006.02 468.x

20. Kim H, Choi GH, Na DC, et al. Human hepatocellular carcinomas with "stemness"-related marker expression: keratin 19 expression and a poor prognosis. Hepatology. 2011;5:1707-1717. doi:10.1002/ hep. 24559

21. Roskams T, Katoonizadeh A, Komuta M. Hepatic progenitor cells: an update. Clin Liver Dis. 2010;14(4):705-718. doi:10.1016/j. cld. 2010.08 .003

22. Ji HN, Rhee H, Kim H, et al. Increased expression of stemness markers and altered tumor stroma in hepatocellular carcinoma under TACE-induced hypoxia: a Biopsy and Resection Matched Study. Oncotarget. 2017;59:99359-99371.

23. Takano M, Shimada K, Fujii T, et al. Keratin 19 as a key molecule in progression of human hepatocellular carcinomas through invasion and angiogenesis. Bmc Cancer. 2016;16(1):903. doi:10.1186/s12 885-016-2949-y

24. Yoneda N, Sato Y, Kitao A, et al. Epidermal growth factor induces cytokeratin 19 expression accompanied by increased growth abilities in human hepatocellular carcinoma. Lab Invest. 2011;91(2):262-272. doi:10.1038/labinvest.2010.161

25. Ku N-O, Strnad P, Bantel H, Omary MB. Keratins: biomarkers and modulators of apoptotic and necrotic cell death in the liver. Hepatology. 2016;64(3):966-976. doi:10.1002/hep.28493

26. Kawai T, Yasuchika K, Ishii T, et al. Keratin 19, a cancer stem cell marker in human hepatocellular carcinoma. Clin Cancer Res. 2015;21(13):3081-3091. doi:10.1158/1078-0432.CCR-14-1936

27. The International Agency for Research on Cancer. WHO Classification of Tumours of the Digestive System (IARC WHO Classification of Tumours). 4th ed. In: Bosman FT, Carneiro F, Hruban RH, Theise ND, editors. World Health Organization; 2010:p5771-418.

28. Liu Y, Hu B, Li Z, He X, Li Y, Lu L. An improved strategy to detect the epithelial-mesenchymal transition process in circulating tumor cells in hepatocellular carcinoma patients. Hepatol Int. 2016;10 (4):640-646. doi:10.1007/s12072-016-9732-7

29. Li TT, Liu H, Li FP, et al. Evaluation of epithelial-mesenchymal transitioned circulating tumor cells in patients with resectable gastric cancer: relevance to therapy response. World $J$ Gastroenterol. 2015;21(47):13259-13267. doi:10.3748/wjg.v21.i47.13259

30. Zhao R, Cai Z, Li S, et al. Expression and clinical relevance of epithelial and mesenchymal markers in circulating tumor cells from colorectal cancer. Oncotarget. 2017;8(6):9293-9302. doi:10.18632/ oncotarget.14065

31. Qi L, Xiang B, Wu F, et al. Circulating tumor cells undergoing EMT provide a metric for diagnosis and prognosis of patients with hepatocellular carcinoma. Cancer Res. 2018;78(16):4731-4744. doi:10.11 58/0008-5472.CAN-17-2459 
32. Wu S, Liu S, Liu Z, et al. Classification of circulating tumor cells by epithelial-mesenchymal transition markers. PLoS One. 2015;4: e123976.

33. Si Y, Lan G, Deng Z, et al. Distribution and clinical significance of circulating tumor cells in nasopharyngeal carcinoma. Jpn J Clin Oncol. 2016;46(7):622-630. doi:10.1093/jjco/hyw046

34. Guo Z, Li L, Jiang J, Ou C, Zeng L, Xiang B. Cancer stem cell markers correlate with early recurrence and survival in hepatocellular carcinoma. World J Gastroenterol. 2014;8:2098-2106. doi:10.3748/ wjg.v20.i8.2098

35. Qi L-N, Ma L, Chen -Y-Y, et al. Outcomes of anatomical versus non-anatomical resection for hepatocellular carcinoma according to circulating tumour-cell status. Ann Med. 2020;52(1-2):21-31. doi:10.1080/07853890.2019.1709655

36. Yasufumi S. The vasohibin family: a novel family for angiogenesis regulation. J Biochem. 2013;1:5-11.

37. Govaere O, Komuta M, Berkers J, et al. Keratin 19: a key role player in the invasion of human hepatocellular carcinomas. Hepatology. 2013;4:674-685.

38. Kim H, Yoo JE, Cho JY, et al. Telomere length, TERT and shelterin complex proteins in hepatocellular carcinomas expressing "stemness"-related markers. J Hepatol. 2013;59(4):746-752. doi:10.1016/ j.jhep.2013.05.011

39. Tsuchiya K, Komuta M, Yasui Y, et al. Expression of keratin 19 is related to high recurrence of hepatocellular carcinoma after radiofrequency ablation. Oncology. 2011;80(3-4):278-288. doi:10.1159/ 000328448

40. Imamura H, Matsuyama Y, Tanaka E, et al. Risk factors contributing to early and late phase intrahepatic recurrence of hepatocellular carcinoma after hepatectomy. J Hepatol. 2003;38(2):200-207. doi:10.1016/S0168-8278(02)00360-4

41. Poon RT, Fan ST, Ng IO, Lo CM, Liu CL, Wong J. Different risk factors and prognosis for early and late intrahepatic recurrence after resection of hepatocellular carcinoma. Cancer. 2000;89:500-507.

42. Portolani N, Coniglio A, Ghidoni S, et al. Early and late recurrence after liver resection for hepatocellular carcinoma: prognostic and therapeutic implications. Ann Surg. 2006;243(2):229-235. doi:10. 1097/01.sla.0000197706.21803.a1
43. Zheng J, Chou JF, Gönen M, et al. Prediction of hepatocellular carcinoma recurrence beyond Milan criteria after resection: validation of a clinical risk score in an international cohort. Ann Surg. 2017;266(4):693-701. doi:10.1097/SLA.0000000000002360

44. Poon RTP. Differentiating early and late recurrences after resection of HCC in cirrhotic patients: implications on surveillance, prevention, and treatment strategies. Ann Surg Oncol. 2009;16(4):792-794. doi:10.1245/s10434-009-0330-y

45. Du Z-G, Wei Y-G, Chen K-F, Li B. Risk factors associated with early and late recurrence after curative resection of hepatocellular carcinoma: a single institution's experience with 398 consecutive patients. Hepatobiliary Pancreat Dis Int. 2014;13(2):153-161. doi:10.1016/ S1499-3872(14)60025-4

46. Xu X-F, Xing H, Han J, et al. Risk factors, patterns, and outcomes of late recurrence after liver resection for hepatocellular carcinoma: a Multicenter Study From China. JAMA Surgery. 2019;154 (3):209-217. doi:10.1001/jamasurg.2018.4334

47. Yang J, Weinberg RA. Epithelial-mesenchymal transition: at the crossroads of development and tumor metastasis. Dev Cell. 2008;14 (6):818-829. doi:10.1016/j.devcel.2008.05.009

48. Thiery JP, Acloque H, Huang RYJ, Nieto MA. Epithelialmesenchymal transitions in development and disease. Cell. 2009;139(5):871-890. doi:10.1016/j.cell.2009.11.007

49. Lee JM, Dedhar S, Kalluri R, Thompson EW. The epithelialmesenchymal transition: new insights in signaling, development, and disease. J Cell Biol. 2006;172(7):973-981. doi:10.1083/jcb.200 601018

50. Kang Y, Massagué J. Epithelial-mesenchymal transitions twist in development and metastasis. Cell. 2004;118(3):277-279. doi:10.10 16/j.cell.2004.07.011

51. Thiery JP, Sleeman JP. Complex networks orchestrate epithelialmesenchymal transitions. Nat Rev Mol Cell Biol. 2006;2:131-142. doi:10.1038/nrm1835
OncoTargets and Therapy

\section{Publish your work in this journal}

OncoTargets and Therapy is an international, peer-reviewed, open access journal focusing on the pathological basis of all cancers, potential targets for therapy and treatment protocols employed to improve the management of cancer patients. The journal also focuses on the impact of management programs and new therapeutic

\section{Dovepress}

agents and protocols on patient perspectives such as quality of life, adherence and satisfaction. The manuscript management system is completely online and includes a very quick and fair peer-review system, which is all easy to use. Visit http://www.dovepress.com/ testimonials.php to read real quotes from published authors. 